\title{
Development of Chinese University Students' Social Responsibility
}

\author{
Boping Liu \\ School of Literature and Law, \\ Northeast Forestry University, China \\ Zhaoqi Liu \\ School of management, \\ Harbin Finance University, China
}

\begin{abstract}
The aim of this study is to find out the development level and the demographic development characteristics of Chinese university students' social responsibility with Chinese university students' social responsibility scale (CUSSRS). 690 students participated in the research. Results show that social responsibility and its dimensions developed in a higher level, the mean of social responsibility is 4.20, the means of four dimensions are 4.35, 4.05, 4.46 and 3.97 respectively. We studies the demographic development characteristics of social responsibility, the t-tests shows that there are significance difference in these aspects: social responsibility $(P=0.050)$ and organization responsibility $(P=0.050)$ in gender; others responsibility $(P=0.006)$ in whether an only child; organization responsibility $(P=0.000)$ in whether a class cadre; others responsibility $(P=0.001)$ in from city or countryside; nature responsibility $(P=0.037)$ and organization responsibility $(P=0.024)$ in whether take part in associations. We hope to give some useful information on cultivating the social responsibility of the students.
\end{abstract}

Keywords: Social responsibility, Development, Citizen, Chinese university students

\section{Introduction}

Cultural, social and technological changes have lead individuals and organizations to fulfill their social responsibilities to work more ethically, in a more humanistic way and more transparently in the context of these changing conditions (Marrewijk, 2003). Silva et al. (2004) argued that social responsibility was important for a well-functioning society. Song (2003) thought that social responsibility was the moral basis for the good development of society and it was indispensable for the construction of a harmonious society, a socially responsible person cared about the stability and the development of the society and devoted his wisdom to the public welfare. Starrett (1996) believed that social responsibility, as a social attitude and social behavior pattern, implied good citizenship within one's community or society. Social responsibility requires respect to the people, public and environment, behaviors consistent with ethic values and in harmony with legal responsibilities (Karna, Hansen and Juslin, 2003). Shek and Cheung (2013) believed that university students, as global citizens and future pillar of society, were expected to contribute to society. Soviet educationalist Makalenko made it clear that cultivating responsibility is an educational means to solve many problems. The studies above show thatsocial responsibility is very important for the society and the individual's responsibility attitude and behavior are indispensable for the construction of the harmonious society. Some researchers have studied the development level of social responsibility. Zhao and Zhang (2010) showed that the development of social responsibility of university students was relatively high. Liu (2011) believed that the social responsibility of university students was above the middle level. The results of Xu (2011) showed that the university students' social responsibility was weakened. Since these results divides greatly, this study focuses on the study of the development level of university students' social responsibility. Also, gender and other demographic features may have impacts on social responsibility, so we studies the demographic development characteristics of social responsibility and its dimensions, and hope we can give some useful information on cultivating the students' social responsibility.

\section{Method}

\subsection{Participants}

The participants included 690 undergraduate students from grade one to grade three, 682 students submitted their questionnaires, the response rate was $98.8 \%$. A missing values analysis was done for the data.The samples reduced to 646. The valid participants included 372 females and 274 males. The average age of thestudents was $19.6(\mathrm{SD}=1.3)$. The statistics for the demographical features of the valid data are showed in table 1. 
Table 1 Statistics for the DemographicFeatures of the Valid Data

\begin{tabular}{|c|c|c|c|}
\hline item & sort & & percent \\
\hline \multirow{2}{*}{ gender } & male & 274 & $42.4 \%$ \\
\hline & female & 372 & $57.6 \%$ \\
\hline \multirow[t]{2}{*}{ Single child } & yes & 344 & $53.3 \%$ \\
\hline & no & 302 & $46.7 \%$ \\
\hline \multirow[t]{2}{*}{ class cadre } & yes & 245 & $37.9 \%$ \\
\hline & no & 401 & $62.1 \%$ \\
\hline From city or & city & 325 & $50.3 \%$ \\
\hline countryside & countryside & 321 & $49.7 \%$ \\
\hline take part in the & yes & 477 & $73.8 \%$ \\
\hline associations & no & 169 & $26.2 \%$ \\
\hline
\end{tabular}

\subsection{Measure}

We use Chinese university students' social responsibility scale (CUSSRS) to measure the development of Chinese university students' social responsibility. It was developed by Liu, Liu and Chen (2017). This social responsibility scale assumes that social responsibility refers to the psychological trait that a citizen assumes his role responsibility consciously, and it considers that university students, especially as a citizen, should undertake responsibility for their country, the nature, the others, and their organizations. Based on these hypothesis, the items of CUSSRS are all concern with the daily life of the university students, it includes 17 items, and has four factors, nation responsibility, nature responsibility, others responsibility and organization responsibility. It has better internal consistency of 0.87 , and the internal consistency reliabilities for nation responsibility, nature responsibility, others responsibility, organization responsibility are $0.831,0.778,0.734$ and 0.710 .The scale also has a better validity. In our study, we are especially concern with the university students' social responsibility from a citizen point of view. We choose this scale as a measurement because it can measure the social responsibility of the university students as citizens.

\subsection{Procedures}

The data collection was done with cluster sampling by convenient. Approval was sought from the school administrators prior to data collection. Participation was voluntary, and a letter of consent was signed by each participant before the survey.

The researcher served as the instructor. An instruction was attached to the questionnaire for explaining the purpose of the research, and the instruction was read by the researcher before the students answered the questionnaires.

\subsection{Analyses}

Analyses were conducted using SPSS 19.0 for windows. Statistical tests were two-sided and the significance level was defined as $\alpha=0.05$.

\section{Results}

\subsection{Developmentlevel of the university students'Social responsibility and its dimensions}

In order to study the university students' development level of social responsibility and its dimensions, we compare means with the valid data $(\mathrm{N}=646)$. The CUSSRS is scored by the five-point Likert-type scoring system, the mid-point is 3. The mean of social responsibility, national responsibility, natural responsibility, others responsibility are higher than 4 , and the mean of organizational responsibility is 3.97 , which is also close to 4 , it means that the development of university students' social responsibility is in a higher level. The result are showed in Table 2.

Table 2 Comparison of means for university students regarding social responsibility and its dimensions.

\begin{tabular}{lll}
\hline & M & SD \\
\hline F1 & 4.35 & 0.746 \\
F2 & 4.05 & 0.632 \\
F3 & 4.46 & 0.531 \\
F4 & 3.97 & 0.677 \\
SR & 4.20 & 0.493 \\
\hline
\end{tabular}

F1=nation responsibility; F2=nature responsibility; F3=others responsibility, F4=organization responsibility, SR=social responsibility. 


\subsection{The demographic development characteristics of social responsibility and its dimensions}

In order to study the development characteristics of social responsibility and its dimensions, $t$-tests were utilized to ascertain the difference in the demographic features.The statistical analysis shows that in gender, whether an only child, a class cadre, from city or countryside and whether take part in associations, there are significant differences. The results are shown from Table 3 to Table7.

Table 3 Differences between genders regarding social responsibility and its dimensions

\begin{tabular}{lllllll}
\hline Factor & Male & female & SD & $t$ & P \\
& M & SD & M & SD & & \\
\hline F1 & 17.28 & 3.054 & 17.48 & 2.931 & -0.858 & 0.391 \\
F2 & 20.05 & 3.183 & 20.43 & 3.134 & -1.484 & 0.138 \\
F3 & 17.64 & 2.275 & 17.95 & 1.998 & -1.797 & 0.073 \\
F4 & 15.62 & 2.699 & 16.04 & 2.703 & -1.965 & 0.050 \\
SR & 70.59 & 8.464 & 71.90 & 8.267 & -1.968 & 0.050 \\
\hline
\end{tabular}

Table 4 Differences between whether an only child regarding social responsibility and its dimensions

\begin{tabular}{|c|c|c|c|c|c|c|}
\hline \multirow[t]{2}{*}{ factor } & \multicolumn{2}{|c|}{ Only child } & \multicolumn{2}{|c|}{ Not only child } & \multirow[t]{2}{*}{$t$} & \multirow[t]{2}{*}{$\mathrm{P}$} \\
\hline & M & SD & $\mathrm{M}$ & SD & & \\
\hline F1 & 17.27 & 2.922 & 17.54 & 3.051 & -1.131 & 0.258 \\
\hline F2 & 20.13 & 3.173 & 20.43 & 3.137 & -1.216 & 0.225 \\
\hline F3 & 17.61 & 2.158 & 18.06 & 2.060 & -2.733 & 0.006 \\
\hline F4 & 15.93 & 2.729 & 15.79 & 2.685 & 0.666 & 0.506 \\
\hline SR & 70.94 & 8.268 & 71.82 & 8.473 & -1.337 & 0.182 \\
\hline
\end{tabular}

Table 5 Differences between whether a class cadre regarding social responsibility and its dimensions

\begin{tabular}{|c|c|c|c|c|c|c|}
\hline \multirow[t]{2}{*}{ factors } & \multicolumn{2}{|c|}{ Class cadres } & \multicolumn{2}{|c|}{ Not Class cadre } & \multirow[t]{2}{*}{$t$} & \multirow[t]{2}{*}{$\mathrm{P}$} \\
\hline & $\mathrm{M}$ & SD & $\mathrm{M}$ & SD & & \\
\hline F1 & 17.50 & 2.861 & 17.33 & 3.057 & 0.687 & 0.492 \\
\hline F2 & 20.23 & 3.063 & 20.29 & 3.218 & -0.256 & 0.798 \\
\hline F3 & 17.88 & 2.223 & 17.78 & 2.063 & 0.572 & 0.567 \\
\hline F4 & 16.56 & 2.416 & 15.44 & 2.789 & 5.237 & 0.000 \\
\hline SR & 72.17 & 7.978 & 70.85 & 8.571 & 1.958 & 0.051 \\
\hline
\end{tabular}

Table 6 Differences between the city and the countrysideuniversity students regarding social responsibility and its dimensions

\begin{tabular}{llllcll}
\hline factor & city & & \multicolumn{3}{c}{ Countryside } & $t$ \\
& M & SD & M & SD & & \\
\hline F1 & 17.22 & 3.000 & 17.57 & 2.965 & -1.486 & 0.138 \\
F2 & 20.21 & 3.191 & 20.33 & 3.128 & -0.462 & 0.644 \\
F3 & 17.56 & 2.242 & 18.09 & 1.965 & -3.198 & 0.001 \\
F4 & 15.90 & 2.706 & 15.83 & 2.713 & 0.327 & 0.743 \\
SR & 70.89 & 8.383 & 71.81 & 8.343 & -1.404 & 0.161 \\
\hline
\end{tabular}

Table 7 Differences between the Students whether taking part in the associations regarding social responsibility and its dimensions

\begin{tabular}{|c|c|c|c|c|c|c|}
\hline \multirow[t]{2}{*}{ factor } & \multicolumn{4}{|c|}{ Taking Part in the Society } & \multirow[t]{2}{*}{$t$} & \multirow[t]{2}{*}{$\mathrm{P}$} \\
\hline & M & SD & M & SD & & \\
\hline F1 & 17.39 & 2.969 & 17.42 & 3.033 & -0.129 & 0.898 \\
\hline F2 & 20.42 & 3.203 & 19.83 & 2.991 & 2.090 & 0.037 \\
\hline F3 & 17.87 & 2.125 & 17.67 & 2.120 & 1.039 & 0.299 \\
\hline $\mathrm{F} 4$ & 16.01 & 2.691 & 15.46 & 2.721 & 2.255 & 0.024 \\
\hline SR & 71.69 & 8.428 & 70.39 & 8.150 & 1.734 & 0.083 \\
\hline
\end{tabular}




\subsubsection{Gender}

When social responsibility and its dimensions undergone a $t$-test, there are significant difference between the male university students and the female university students for organization responsibility and social responsibility. The total score of social responsibility of female students was higher than that of the male, and the difference was significant $(\mathrm{p}=0.05)$. For the organization responsibility, the female' was higher than that of the male, and the difference was significant $(\mathrm{p}=0.05)$. For other responsibility, the female' was higher than that of the male, but there is no significant difference. See table 3 .

\subsubsection{Whether an Only Child}

Regarding whether an only child, the t-test results show statistically significant difference for others responsibility $(\mathrm{p}=0.006)$, which showed that the others responsibility of the not only child was higher than that of the only child, and the difference was significant, for social responsibility and its other dimensions, there is no significant difference. See table 4.

\subsubsection{Whether a Class cadre}

There is significant difference between the class cadre and the not class cadre university students $(\mathrm{p}=0.000)$ for organization responsibility when social responsibility and its dimensions undergone a t-test. The organization responsibility of class cadres is higher than that of not class cadres. The results are showed in Table 5.

\subsubsection{From city or countryside}

University students from city or from countryside may have differences in social responsibility and its dimensions. The t-test results show statistically significant difference for others responsibility $(p=0.001)$, which showed that the others' responsibility of the university students from countryside was higher than that of the city university Students, and the difference was significant, for social responsibility and its other dimensions, there is no significant difference. The city university students' organizational responsibility is higher than that of the countryside university students, but there is no significant difference. See table 6.

\subsubsection{Whether taking part in the associations}

Taking part in student' associations is a very important part for university students' life. Regarding whether taking part in the associations, the t-test results show statistically significant differences for nature responsibility $(\mathrm{p}=0.037)$ and organization responsibility $(\mathrm{p}=0.024)$, which showed that the others responsibility and the organization responsibility of students who taking parting in the associations are higher than that of the student who does not taking part in the associations, and the difference was significant, for social responsibility and its other dimensions, there is no significant difference. See table 7.

\section{Discussion}

This study shows that the development level of the university student' social responsibility is higher. The mean of social responsibility is 4.20, and the result is close to the result of Zhao and Zhang (2007) and opposite to the results of $\mathrm{Xu}$ (2011). The mean of each dimension of the university students' social responsibility are also higher, which the means of others responsibility, nation responsibility and natural responsibility are all above 4, and the mean of organizational responsibility is 3.97 , which is close to 4 .

The higher development level of social responsibility is because of the high light of the social responsibility education in the family and the school. Soviet educationalist Makalenko considered that the excellent character comes from the profound family education. Most of Chinese parents are good examples for the children in undertaking their social responsibility. Higher social responsibility comes from good example. For schools social responsibility education, early in February 1995, the State Education Commission issued the outline of moral education for middle school, this document regarded the cultivation of student as social responsibility citizens as one of the education moral goals in senior high school. Later, a series of official authoritative documentsissued, such as the outline of moral education in universities issued in November 1995, and the other documents concerned with responsibility issued in the august,2004 and October,2013. These documents all reflects that the party and the state regard the cultivation of the responsibility of middle school students and university students as an important goal of school moral education, and emphasizes that school education should play the main role in youth responsibility education. University social responsibility is about the need to strengthen civic commitment and active citizenship; it is about volunteering, about an ethical approach, developing a sense of civil citizenship by encouraging the students, the academic staff to provide social services to their local community or to promote ecological, environmental commitment for local and global sustainable development (Vasilescu et al. 2010). All these beliefs help promote the university students'social responsibility. 
The demographic development characteristics of social responsibility also studied in this paper. The development of each social responsibility dimension of the female university students are higher than that of male students. This can be explained by the growth process of female university students. In the process of growing up, female university students are more internalize the values of the school education and the family guidance, so the degree of their compliance with social norms is higher than male students, and this bring about their higher development of nation responsibility, nature responsibility, others responsibility and organization responsibility. This result in the female' social responsibility are higher than the male and the difference is significant.

In addition, the females' others responsibility is higher than that of the male students, which can be explained by the Chinese traditional educational believes. Chinese traditional believes require females to be considerate, gentle and kind. Accordingly, in the family rearing style, parents also cultivate the gentle and kind-hearted character of females. As a result, females who grow up in such a family rearing style are more sensitive and compassionate to the living conditions of others, so they are more aware of the others'need, and more sympathetic to vulnerable groups. On the contrary, for the traditional Chinese believes, males are required to be stronger instead of too delicate, so the character of males who are trained in this way are more rough, so they are less sensitive than girls in understanding the living conditions of others.

The development of female university students' organizational responsibility is higher than that of male students and the difference was significant. On the one hand, the female students internalize more the values of the school education and of the family guidance than the male students; on the other hand, compared with males which emphasize personality independence, females are more internalize the requirements of organizational values, and this enhance their organization responsibility.

The development level of others responsibility of the not only child university students is higher than that of the only child university students. There are some difference in family rearing styles between the only child family and the not only child family. In the only child family, the parents' overindulgence is more common, and the self-centeredness being strengthened, so the egocentrism is more obvious in some of the only child, and this make them lack of caring for others.

The development level of organizational responsibility of the class cadres is higher than that of the non-class cadre. Generally speaking, class cadres are students who are relatively excellent in many aspects and have relatively strong organizational abilities. Most of them have been serving as class cadres from primary school to university. Serving as a class cadre requires the class cadres must first do what the ordinary students are required to do, and this promote their organization responsibility. They are more active in participating in collective activities, usually, they are organizers and leaders in organizations such as student associations, and are more concerned about the honor of the organization. All these promote the development of their organization responsibility.

There are significant differences in others responsibility between countryside university students and city university students, which shows that the development of countryside university students'others responsibility is higher than that of city university students. Because of the particularity of growing up environment, university students in the countryside witness and feel the hardship of people, and have a more direct feeling for the suffering of the others. Their ability to understand other people' sufferings is higher than that of city university students, thus showing a higher level of responsibility for others. Moreover, the characteristics of living environment in countryside communities make the interaction much higher between countryside residents than that between cities residents. Frequent and close interpersonal interaction makes individuals in countryside feel more about helping others and show a higher level of others responsibility.

There are significant differences in natural responsibility and organization responsibility between university students who take part in the associations and those students who do not. The natural responsibility and organizational responsibility of university students who taking parting in the association are higher than those of who do not.

The university association has educational functions. Some student associations focus on the protection of nature, which to some extent enhances the natural responsibility of university students. The students who take part in associations have direct contact with nature and the society, and this makes them feel directly the necessity of nature conservation. Therefore, the development level of natural responsibility of university students participating in the association is higher than that of the university students who do not.

The students associations require the university students abide by the organizational discipline, such as to have a meeting and to fulfill their task on time. Gradually, university students participating in the association abide by the organizational discipline of the associations consciously, and thus improve the organizational responsibility of the students. 
In this study, we measures the development lever of social responsibility with the CUSSRS, a scale that concern more about the university students' social responsibility from a citizen point of view. This make the study has its own significance and different from the studies before, which most of the social responsibility studies relate to the corporate social responsibility (CSR). Also, we study the demographic development characteristic of the university students' social responsibility, so that we can know more about the factors that influence the formation of social responsibility, and hope the study will give some useful information for the cultivation of the university students' social responsibility.

\section{References}

Karna, J., Hansen, E., \& Juslin, H. (2003). Social responsibility in environmental marketing planning. European Journal of Marketing, 37 (5/6), 848, 871.

Liu, B. P., Liu, Z. Q., Chen, L. (2017). Development of a social responsibility scale for Chinese university students. Current Psychology, [Online] Available: https://doi.org/10.1007/s12144-017-9743-0.

Liu, H. T., Zheng, X., Liu, Y. G. (2011). The influencing factors and the development characteristics of university student' social responsibility. Journal of Ningbo University, 20 (1), 77-79.

Marrewijk, M V. (2003). Concepts and definitions of CSR and corporate sustainability: between agency and communion. Journal of Business Ethics, 44(2/3), 95- 105.

Raymond, H. S. (1996). Assessment of global social responsibility. Psychology Report,78:535-554.

Shek, D. T. L., \& Cheung, B. P. M. (2013). Developmental issues of university students in Hong Kong. Journal of Adolescence Medical Health, 25(4), 345-351.

Silva, L. D., Sanson, A., Smart, D., \& Toumbourou, J. (2004). Civic responsibility among Australian adolescents: Testing two competing models. Journal of Community Psychology, 32(3), 229-255.

Song, Y. (2003). The moral connotation and realization mechanism of responsibility formation. Journal of Nanjing University, 4, 89-93.

Vasilescu, R., Barna, C., Epure, M.,\& Baicu, C. (2010). Developing university social responsibility: A model for the challenges of the new civil society. Journal of Procedia Social and Behavioral Sciences 2, 4177-4182.

$\mathrm{Xu}$, Z. (2011). An Empirical Study on the Cultivation of the Social Responsibility of the Contemporary university Students. Education and Educating Forum.29,15-18.

Zhao, X. K., Zhang, D. J., Liu, Z. F. (2010). Research on the development characteristic of the social responsibility of the university students. Journal of Mudanjiangeducational department, 2, 78-79. 